\title{
Potential Economic Damage from Introduction of Brown Tree Snakes, Boiga irregularis (Reptilia: Colubridae), to the Islands of Hawai ${ }^{1}{ }^{1}$
}

\author{
Stephanie A. Shwiff, ${ }^{2,4}$ Karen Gebhardt, ${ }^{2}$ Katy N. Kirkpatrick ${ }^{2}$, and Steven S. Shwiff ${ }^{3}$
}

\begin{abstract}
The Brown Tree Snake (Boiga irregularis) has caused ecological and economic damage to Guam, and the snake has the potential to colonize other islands in the Pacific Ocean. This study quantifies the potential economic damage if the snake were translocated, established in the state of Hawai $i$, and causing damage at levels similar to those on Guam. Damages modeled included costs of medical treatments due to snakebites, snake-caused power outages, and decreased tourism resulting from effects of the snake. Damage caused by presence of the Brown Tree Snake on Guam was used as a guide to estimate potential economic damage to Hawai'i from both medical- and power outage-related damage. To predict tourism impact, a survey was administered to Hawaiian tourists that identified tourist responses to potential effects of the Brown Tree Snake. These results were then used in an input-output model to predict damage to the state economy. Summing these damages resulted in an estimated total potential annual damage to Hawai'i of between \$593 million and \$2.14 billion. This economic analysis provides a range of potential damages that policy makers can use in evaluation of future prevention and control programs.
\end{abstract}

The Brown Tree Snake, Boiga irregularis (Merrem), arrived accidentally on Guam, an island in Micronesia, shortly after World War II, probably as a stowaway on U.S. military cargo ships from the New Guinea area (Fritts and Rodda 1998). Without any natural predators or parasites on Guam, and with an abundant prey base, the snakes increased in number dramatically. The Brown Tree Snake is a mildly venomous generalist predator with grooved, venom-conducting fangs at the rear

\footnotetext{
${ }^{1}$ This study was funded by the U.S. Fish and Wildlife Service and Office of Insular Affairs. Manuscript accepted 25 March 2009.

2 USDA/APHIS/WS, National Wildlife Research Center, 4101 LaPorte Avenue, Fort Collins, Colorado 80521-2154 (phone: 970-266-6150; fax: 970-266-6157).

${ }^{3}$ Department of Accounting, Economics, and Finance, Texas A\&M University-Commerce, Commerce, Texas 75428 .

${ }^{4}$ Corresponding author (e-mail: Stephanie.A.Shwiff@ aphis.usda.gov).
}

Pacific Science (2010), vol. 64, no. 1:1-10

doi: 10.2984/64.1.001

(C) 2010 by University of Hawai'i Press

All rights reserved of the maxillae (Fritts et al. 1994, Fritts and Rodda 1998). It is abundant in many habitats in both urban and rural areas and is successful in maintaining high densities near human populations (Fritts and Chiszar 1999, Engeman and Vice 2001).

The Brown Tree Snake has caused human health concerns, power outages, and the extirpation of 10 of 13 native bird species on Guam (Savidge 1987, Fritts 1990, Fritts et al. 1994, Rodda et al. 1997, Fritts and Rodda 1998, Fritts and Chiszar 1999, Fritts and McCoid 1999, Fritts 2002). Although extensive research has been conducted on the biology and habitat of the snake and on efforts to control the movement of the snake (Fritts and Chiszar 1999, Rodda et al. 1999, Savarie and Bruggers 1999, Engeman and Vice 2001, Burnett et al. 2008), few studies have measured the economic damages (except for power outages) caused by the snake on Guam (Fritts 2002). The only study that estimated the potential damage of the snake in Hawai'i (Burnett et al. 2008) utilized preliminary results from the study reported here.

Islands are especially vulnerable to biological invasions because their human populations import large amounts of food and other 
goods, and Guam is a major transportation center for both civilian and military traffic in the central Pacific region. Of particular concern is the potential transportation of Brown Tree Snakes to the islands of Hawai'i (Kraus and Cravalho 2001). Like Guam, Hawai'i has no endemic terrestrial snakes (Fritts et al. 1994), and despite intensive cargo-screening measures to prevent the snake from leaving Guam, eight Brown Tree Snakes have been found on O'ahu since 1981, transported on commercial and military aircraft from Guam (Fritts et al. 1999, Burnett et al. 2008).

Research on the economics of invasive nonnative species has focused primarily on four areas: the effect of invasive species on agriculture, including forestry and fisheries; impacts on human health; determining the probabilities of invasion and colonization; and the prevention, eradication, and control of invasive species (Knowler and Barbier 2000, Perrings et al. 2000, 2005, Born et al. 2005, Pimentel et al. 2005, Olson 2006). Published studies have provided retrospective analyses of the damage of the invasive species (Born et al. 2005). Many have tended to examine only one area of damage caused by a particular species, or have focused on biological impacts of the species as opposed to economic damage to tourism, commodity markets, institutions, or property rights (Perrings et al. 2005). Uncertainty surrounding the economic impact of invasive species tends to narrow the focus of invasive species economic research (Born et al. 2005), and examining existing invasions may reduce uncertainty by guiding predictions of potential damage in other settings (Perrings et al. 2000).

This analysis collected information on medical incidents and power outages on Guam and used it to guide estimates of potential damage to Hawai'i. Data on potential impacts to tourism were not available from Guam and were collected for Hawai' $i$ through a survey conducted on $\mathrm{O}^{\prime}$ ahu in January 2008. These three areas of damage do not represent all areas of snake-caused economic damages but are important areas of damage for which data sources were available or for which accurate estimates could be made. The exclusion of other damages contributes to the conservative nature of this analysis. For example, the Brown Tree Snake has extirpated 10 of 13 native bird species on Guam (Savidge 1987), and this loss of native avifauna has permanently altered the island's environmental and ecological characteristics. Additional impacts such as this fall outside the scope of this study.

\section{MATERIALS AND METHODS}

For the purposes of this study, Guam was used as a benchmark for comparative estimates of Brown Tree Snake damages to Hawai' $i$, and therefore it is assumed that the probability of snake invasion, establishment, and ability to convey real economic damage in Hawai' $\mathrm{i}$ is $100 \%$. The total (hypothetical) annual damages associated with the Brown Tree Snake in Hawai' 1 i were estimated as the sum of all medical, power outage, and tourism costs. We assumed that the prevalence of medical incidents and power outages on Guam provided an indication of the expected prevalence in Hawai' $i$ and that extrapolation was an appropriate means by which to predict economic damage to Hawai'i.

Direct extrapolation of damage to the tourism sector was not possible because this information was not available for Guam. In addition, the complexity and uniqueness of each island economy makes direct extrapolation of this variable potentially spurious. For this analysis, the most accurate way to estimate the potential Brown Tree Snake damages to tourism was to utilize an inputoutput (IO) model of the Hawaiian economy and to survey tourists in Hawai'i (O'ahu) to determine their stated changes to tourism given the effects of the Brown Tree Snake. An IO model creates a sophisticated mathematical representation of the state economy to predict the effects of changes in one industry on others. An IO model was used to capture all of the impacts (direct, indirect, and induced) to estimate a total level of impact of a hypothetical decrease in tourism related to the Brown Tree Snake. Inputs into the IO model were gleaned from data collected by survey on O‘ahu during January 2008. 


\section{Projecting Medical Impacts}

Two hospitals on Guam treated human injuries caused by Brown Tree Snakes during the study period. Guam Memorial Hospital treated civilians, and the U.S. Naval Hospital Guam served military personnel stationed on Guam. Records of patients treated for snakebites were collected for a 7-yr period (19982004) from Guam Memorial Hospital; however no bite treatments were recorded at the naval hospital. Data from Guam Memorial Hospital indicated that about 170 human snakebite incidents occurred on Guam each year.

Previous studies indicated that bites and subsequent hospitalizations often occurred to victims asleep in their homes and that infants $(0-1 \mathrm{yr}$ old $)$ and young children $(<10 \mathrm{yr})$ constituted a high percentage $(>50 \%)$ of the snakebite victims taken to emergency medical facilities in Guam (Fritts 1990, Fritts et al. 1994, Haddock and Cruz 1996, Fritts and McCoid 1999). However, the data collected for our study suggested a more evenly balanced distribution of victims' ages. Our data indicated that infants and young children (21\% of Guam's population [U.S. Census Bureau 2007]) represented $28.7 \%$ of bite victims who visited the hospital. According to Guam Memorial Hospital medical records, the mean cost to treat an individual was $\$ 288$ per hospital visit, and the total average annual costs were $\$ 48,631$.

Guam's experience was used to project the potential medical damages in Hawai'i. If the snake density is assumed to be the same as on Guam, higher levels of urbanization in Hawai' $i$ would arguably cause a potential decrease in the overall number of snakebites. This decrease could be tempered by the higher proportion of Hawaiians living in rural areas (9\%) as compared with Guamanians (7\%) (U.S. Census Bureau 2007). Due to these uncertainties, a conservative range of snakebite incidence in Hawai'i was extrapolated at $50 \%, 75 \%$, and $100 \%$ of the frequency documented on Guam. For example, using U.S. census population estimates from 2000 , an annual average of 170 bites requiring hospital admission on Guam equates to a snakebite frequency of 110 bites per 100,000 residents. A hypothetical frequency of $75 \%$ of the level on Guam would equate to 82.5 bites per 100,000 residents in Hawai' $i$. In addition, it was estimated that medical costs were similar enough between Hawai'i and Guam to ignore any potential differences in average treatment costs.

\section{Projecting Power Impacts}

Power outages caused by Brown Tree Snakes have been a serious problem on Guam for more than $30 \mathrm{yr}$, and the documented annual incidence of snake-caused outages increased 15-fold from 13 in 1978 to nearly 200 in 1997 (Fritts 2002). Two power facilities operated on Guam at the time of this analysis. Guam Power Authority provided services to the civilian population, and the Naval Public Works Electrical Generation Unit provided power to the naval base. Snake-caused power outage data were provided by the Guam Power Authority for a 1-yr period from 11 March 2003 to 10 March 2004, and the Naval Public Works provided information for the 2003 calendar year. On average, snake-caused power outages affecting Guam Power Authority occurred every 1.8 days, and the $\mathrm{Na}$ val Public Works experienced snake-caused power outages once every 8.8 days. Summing the total grid time, Guam experienced a total of $403 \mathrm{hr}$ of power outage in both large and small distribution areas due to the Brown Tree Snake.

Guam's experience was used to project the potential power damages in Hawai'i. Guam has 663 miles (about 1,061 km) of transmission and distribution lines, and Hawai' $i$ has approximately 3,000 miles (about 4,838 km) (Guam Power Authority 2008, Hawaiian Electric Company 2008). The extrapolation from Guam was adjusted because although there are many more miles of transmission and distribution lines in Hawai' $i$ than on Guam, $40 \%$ of the power lines in Hawai' $i$ are buried lines that are impervious to a snake-caused outage, thereby reducing the total predicted outage hours.

To determine the monetary damage of snake-caused power outages in Hawai'i, we 
used an estimated 1-hr-long power outage cost reported by Fritts (2002). Fritts determined that an 8- to 12-hr-long, islandwide power outage on O'ahu in 1991 cost an estimated $\$ 20$ to $\$ 64$ million in lost productivity (between $\$ 1.6$ and $\$ 8$ million per hour). This estimate refers to an islandwide outage; however many snake-caused outages would occur to smaller distribution areas on $\mathrm{O}^{\prime}$ ahu and other islands. Therefore, we used the lowest estimated cost of $\$ 1.6$ million per hour for the upper-limit cost of power outages in $\mathrm{Ha}$ waici. Fritts (2002) estimated that 36\% of snake-caused power outages in Guam were listed "at large," meaning the outage affected a large segment of the circuit, the entire circuit, or multiple circuits. Using this information, we developed a hypothetical pattern of power outages in Hawai'i as follows: 10\% occurring at the magnitude of \$1.6 million per hour, $20 \%$ occurring at $50 \%$ of that magnitude, $30 \%$ occurring at $25 \%$ of that magnitude, and $40 \%$ occurring at $10 \%$ of that magnitude.

Additional potential damages to the Hawaiian electrical system associated with Brown Tree Snake-caused power outages were not quantified, such as added costs of repairs to the electrical generation and distribution system, costs in lost revenues to the power-generating entities, and costs to electrical customers such as damages to electrical equipment and appliances and the installation, operation, and maintenance costs of emergency generation of electricity (Fritts et al. 1987, Fritts 1988, 2002).

\section{Projection of Tourism Impacts}

Numerous factors influence the demand for tourism including the income of visitors, transportation costs to the destination, relative prices, the currency exchange rate, and qualitative factors such as destination attributes (Lim 2006). The Hawai'i Department of Business, Economic Development, and Tourism conducts annual surveys of recent visitors and collects information on visitor activities (a subset of qualitative factors of the destination) such as sightseeing, recreation, shopping, and cultural activities (Hawai'i De- partment of Business, Economic Development, and Tourism 2007). None of these activities would be beyond the sphere of influence of the Brown Tree Snake if the snake were present in Hawai' $i$.

Due to the importance of tourism to the Hawaiian economy and the lack of empirical benchmark data on impacts to tourism on Guam, a survey of the three current major source markets for tourists (U.S. West, U.S. East, and Japan) was performed in January 2008 (S.A.S., unpubl. data). The objectives of the survey were to specify the potential change in the number of visitor days from major market areas and to assess the relative importance of snake presence in choosing Hawai' $i$ as a tourist destination.

A survey company was contracted to conduct intercept surveys of the visitors from the three major source markets at four O'ahu, Hawai'i, locations: Hanauma Bay, Waikīkī Shopping District, Waikīkī Kūhīō Beach/Kapi'olani Park, and Waimea Valley. Surveys were conducted by speakers fluent in Japanese and English, and a total of 809 surveys was completed, involving respondents from the continental United States, Japan, and other countries. Responses were analyzed and weighted to be proportionate to the composition of tourists from the three major source markets visiting Hawai'i using data from the Hawai'i Department of Business, Economic Development, and Tourism.

The survey questions used in this economic analysis were based upon a given scenario, a description of which was read aloud to the respondent and provided in a text format. The scenario was described as follows: "The Brown Tree Snake is a semi-poisonous snake that is abundant on Guam, another island in the Pacific Ocean. On Guam, the snake has been damaging to the bird population and has caused the extinction of $75 \%$ of native bird species. Each year on Guam, approximately 1 in every 1,000 people is bitten by the snake. On Guam, the snake causes local to island-wide power outages every other day. On Guam, trade has been affected. For example, outgoing cargo is delayed for searches for the snake. Currently, there are no snakes in Hawai'i. Hawai'i and Guam have a similar habitat and it is possible that 
the Brown Tree Snake could accidentally become established here. So far, eight Brown Tree Snakes have been found in Hawai'i."

The two questions utilized in this analysis queried how tourists would have altered their current and future vacation plans in Hawai'i. The first key question asked, "Knowing this information, when planning your current trip to Hawaici, if you had known that the Brown Tree Snake was established here and having the same effects as on Guam, would you have: visited Hawai'i for more days (how many days), visited Hawaili for the same number of days, visited Hawai'i for fewer days (how many days), or selected a different destination instead of Hawai'i." Overall, in comparison with respondents' current vacation plans, $88.1 \%$ of the respondents stated that they would have vacationed in Hawai' $i$ for the same number of days, $2.4 \%$ would have visited fewer days, $8.8 \%$ would have selected a different vacation destination instead of Hawai'i, and $0.7 \%$ would have increased the duration of their current vacation. If total visitation for 2007 from the three source markets was 56,769,403 visitor days (Hawai' $i$ Department of Business, Economic Development, and Tourism 2007), this would represent a decrease of 5,081,425 (9.05\%) visitor days (S.A.S., unpubl. data).

The second key question inquired about a hypothetical 10-day future trip: "Suppose you are planning a vacation to a tropical island for 10 days next year and one of your options is Hawaili. You learn that the Brown Tree Snake is established in Hawai' $i$ and now you may encounter less birds overall, fewer native birds, the possibility of a snake encounter, and the increased possibility of a power outage, would you plan to: visit $\mathrm{Ha}-$ wai'i for more days (how many days), visit Hawai' $i$ for the same number of days, visit Hawai'i for fewer days (how many days), select a different destination instead of Hawai'i, or the Brown Tree Snake impacts would NOT factor into my vacation decision making." If the Brown Tree Snake was established and causing similar damages, $50.5 \%$ of the respondents indicated that they would visit Hawai'i for 10 days, $4.1 \%$ would visit Hawai' $i$ for fewer than 10 days, $20.6 \%$ would select a different destination than Hawai'i,
$0.9 \%$ would visit Hawai'i for more than 10 days, and $23.8 \%$ stated that the Brown Tree Snake damages would not factor into their vacation decision making. This would represent a decrease of $12,816,319(23.52 \%)$ visitor days from the 2007 level (S.A.S., unpubl. data).

To estimate the total impact to the Hawaiian economy of the potential decrease in tourism, an IO model was used (Minnesota IMPLAN Group, Stillwater, Minnesota). An IO model is a mathematical representation of a regional (city, county, state, etc.) economy that contains all the linkages among economic sectors (e.g., agricultural, manufacturing, and industrial). The direct economic effect of decreased visitor days in each source market was the loss of tourist spending for lodging, meals, entertainment, shopping, and so forth based on responses to both key survey questions. For example, when the number of tourists (or visitor days) decreases, fewer dollars are spent at souvenir shops. This means that the shop owner receives less profit (the direct effect), but in addition the shop owner purchases fewer crafts from local Hawaiian artisans for resale. As a result, those local artisans have less income to spend in the local regional economy. These secondary impacts, consisting of indirect and induced effects, can be calculated as they ripple throughout the Hawaiian economy. Leakages from the economy also exist and represent any flow of money that does not stay in the regional economy, for example when the same shop owners purchase souvenirs made in China.

IO modeling is an accepted methodology for estimating the secondary impacts in an economy based on the most current economic and demographic data available (Bureau of Economic Analysis 2008). Detailed descriptions of the relationships among economic sectors in the IO model are discussed extensively in the economic literature (Blair 1995, Bon 2000, Lahr and Dietzenbacher 2001, Loomis and Helfand 2001, McCann 2001). The IO model used reflects the 2002 regional-level industry activity and the 2002 Bureau of Economic Analysis' accounting of industrial linkages. Further, the IO model was updated by a method referred to as 
ground proofing. This means firms were added or deleted from each regional economy based on current state-level economic data. IO modeling has been used extensively by the Hawai'i Department of Business, Economic Development, and Tourism to capture the effects of tourism changes to the Hawaiian economy (see Hawai'i Department of Business, Economic Development, and Tourism 2003, 2004, 2008, Bureau of Economic Analysis 2008). This type of modeling is widely used in economic forecasting and urban economic studies because it allows for the prediction of output flows among different sectors of the economy in response to an input change and it can be especially useful for sensitivity analysis (McCann 2001).

\section{Sensitivity Analysis}

The economic calculations in this analysis were constructed as a series of ranges in an attempt to recognize uncertainty about the magnitude of the predicted economic damages and the costs assigned to them. They were created by using the Guam experience as a benchmark and by making plausible estimates of the unknown quantities. A sensitivity analysis was included to estimate the uncertainty within the calculations and to examine how sensitive the results were to a change in each area of damage. For medical damages, the sensitivity analysis is expressed in the varied levels of predicted damage in Hawai' $i$ (i.e., $50 \%, 75 \%$, and $100 \%$ ) based on the actual damage on Guam. For poweroutage damages, the sensitivity analysis varied (by increments of $25 \%$ ) the level of damage directly extrapolated from Guam. For the im- pacts to tourism, the $\mathrm{IO}$ analysis incorporated a range of reduction in tourist days caused by the presence of the Brown Tree Snake. This range extended from a $1 \%$ minimum baseline estimate, through a midrange reduction of $5 \%$, to a maximum $10 \%$ reduction in visitor days, which was based upon the lower of two values $(9.05 \%)$ reported by tourists surveyed on O'ahu.

\section{RESULTS}

If the Brown Tree Snake becomes established in Hawai' $i$, the total estimated potential annual damage from medical damages, poweroutage costs, and the cost of a decrease in tourism would range from approximately $\$ 593$ million to $\$ 2.14$ billion (Table 1). This analysis projected that in Hawai' $i$, at all levels of total potential annual damage, medical costs composed the smallest portion, making up less than $1 \%$ of the total costs. Power outages would compose the majority (approximately $77 \%$ ) of the total costs at the lowest damage estimates; at the highest, however, power outage-related costs (approximately $36 \%$ ) would fall below damage resulting from a decrease in tourism (approximately $64 \%)$.

The estimated potential range of annual snakebite-related injuries in Hawai' $i$ was between 665 and 1,330 individuals, with a cost ranging from $\$ 191,520$ to $\$ 303,040$ (Table 2 ). At the midrange estimate ( $75 \%$ of Guam's bite frequency), it was projected that approximately 997 individuals would receive medical care each year in Hawai'i due to Brown Tree Snake bites. The total annual power outage duration in Hawai'i was projected at 1,209 hr

TABLE 1

Estimated Annual Brown Tree Snake-Caused Total Annual Damage to Hawai'i

\begin{tabular}{llll}
\hline \hline Type of Damage & Low Estimate & Mid Estimate & High Estimate \\
\hline Medical impact & $\$ 191,520$ & $\$ 287,136$ & $\$ 383,040$ \\
Power impact & $\$ 456,000,000$ & $\$ 609,000,000$ & $\$ 761,000,000$ \\
Tourism impact & $\$ 137,779,000$ & $\$ 688,895,000$ & $\$ 1,377,791,000$ \\
Total damage & $\$ 593,970,520$ & $\$ 1,298,182,136$ & $\$ 2,139,174,040$ \\
\hline
\end{tabular}


TABLE 2

Estimated Annual Brown Tree Snake-Caused Medical Impact in Hawai' $i$

\begin{tabular}{lrr}
\hline \hline Parameter & No. of Patients & Annual Cost \\
\hline Extrapolated low estimate (50\% bite frequency) & 665 & $\$ 191,520$ \\
Extrapolated mid estimate (75\% bite frequency) & 997 & $\$ 287,136$ \\
Extrapolated high estimate (100\% bite frequency) & 1,330 & $\$ 383,040$ \\
\hline
\end{tabular}

TABLE 3

Estimated Annual Brown Tree Snake-Caused Power Impact in Hawai'i

\begin{tabular}{lrr}
\hline \hline Parameter & Time (hr) & Annual Cost \\
\hline Power outages decrease by 25\% (low estimate) & 906 & \$456 million \\
Extrapolated mid estimate & 1,209 & \$609 million \\
Power outages increase by 25\% (high estimate) & 1,511 & $\$ 761$ million \\
\hline
\end{tabular}

TABLE 4

Estimated Annual Brown Tree Snake-Caused Tourism Impact in Hawai'i

\begin{tabular}{|c|c|c|c|}
\hline$\%$ Decrease in Tourism: $1 \%$ (Low & Estimate) & 5\% (Mid Estimate) & 10\% (High Estimate) \\
\hline Job loss & 1,399 & 7,000 & 13,000 \\
\hline Direct impact & $\$ 75,545,000$ & $\$ 377,725,000$ & $\$ 755,450,000$ \\
\hline Indirect and induced impact & $\$ 62,234,000$ & $\$ 311,170,000$ & $\$ 622,341,000$ \\
\hline Total annual tourism impact & $\$ 137,779,000$ & $\$ 688,895,000$ & $\$ 1,377,791,000$ \\
\hline Final demand multiplier & & 1.82 & \\
\hline
\end{tabular}

(Table 3). The results of the sensitivity analysis provided a range in costs from $\$ 456$ million to $\$ 761$ million per year. A 25\% change would equate to a difference in value of approximately $\$ 150$ million. The potential range of total tourism impacts is shown in Table 4. This range includes hypothetical $1 \%, 5 \%$, and $10 \%$ decreases in the expected number of tourist days spent in Hawai'i due to the presence of the Brown Tree Snake. Summing the direct, indirect, and induced impacts yields an estimate of the total economic damage from a reduction in tourism of between $\$ 138$ million and $\$ 1.38$ billion per year.

The final demand multiplier of 1.82 means that for every dollar spent by a tourist to Ha- wai' $i, \$ 1.82$ of spending was generated in the economy. Conversely, every dollar that the presence of the Brown Tree Snake prevents from being spent in the Hawaiian economy generates a $\$ 1.82$ loss. This multiplier gives an indication of the importance of tourist spending on the Hawaiian economy. In addition to spending impacts, for every $\$ 1$ million of tourist spending lost, approximately 18.5 jobs would be lost. Therefore, the most conservative $(1 \%)$ estimate of the impact of the snake on tourism would be a loss of approximately \$138 million in tourist-generated revenues and a loss of about 1,400 jobs. At the highest $(10 \%)$ estimate, almost $\$ 1.4$ billion in revenue and about 13,000 jobs would be lost. 
DISCUSSION

Results of this study indicated that the introduction of the Brown Tree Snake to Hawai'i would cause damages in the areas of medical incidents, power outages, and reduced tourism. The greatest economic damage would result from potential impacts to tourism and power, and the smallest would result from medical incidents. We sought to conservatively estimate the economic damages associated with the hypothetical establishment of the Brown Tree Snake in Hawai'i, using actual damage levels on Guam as benchmarks. Incorporation of additional costs of the snake invasion (e.g., native bird extirpation and trade impacts) as sources of potential damages to Hawai'i undoubtedly would have increased the overall levels of damages.

This study illuminated several misconceptions and provided new information related to the effects of the Brown Tree Snake. First, although medical incidents had garnered much attention for the apparent preponderance of children as victims, our data indicated that children were not as likely to be bitten by Brown Tree Snakes as reported in previous research. Further, the economic costs associated with medical incidents resulting from Brown Tree Snake-caused bites were inconsequential when compared with the costs associated with power outages and decreased tourism. Second, power outages related to the snake occurred with greater frequency than previously reported, and associated damages exceeded previous estimates. Last, incorporation of a survey instrument provided previously unavailable data as to the stated preferences of tourists related to the presence of this invasive species.

There were several limitations to our study. First, in questioning tourist opinion, as with the use of any survey instrument, we acknowledge that biases exist and that results are the stated preferences of individuals and not their actual behavior. This survey was written in an effort to minimize these biases and to provide realistic responses from tourists. Second, using Guam as a benchmark provided a single point to estimate damages due to the potential presence of the Brown
Tree Snake in Hawai'i. However, it has been argued that one way to study the potential impact of invasive species at a new location is to use existing locations as benchmarks ( $\mathrm{Pi}$ mentel et al. 2005). Additional future studies may be able to extrapolate from other locations that are impacted by invasive species or estimate damages based on quantitatively derived projections of snake population growth and survival. Finally, we note that modification of the assumptions regarding the levels of prevention, control, and establishment of the snake would provide alternate total estimates of damages. The incorporation of climate and habitat factors into the snake's invasion potential, when feasible, could provide further insight into potential economic damage. These current limitations are important issues that should be addressed in future research.

Economic impacts are one of the many factors that play a role in determining the likelihood of funding for programs to control invasive species. This study revealed that if Guam is a representative benchmark to the possible effects of the establishment of the Brown Tree Snake in Hawai'i, the snake's invasion and establishment would have potentially permanent and costly economic consequences.

\section{ACKNOWLEDGMENTS}

We thank Kim Burnett, Gordon Rodda, Jim Gionfriddo, Ray Sterner, and Kathy Fagerstone. Appreciation goes to Earl Campbell and Karl Buermeyer at the U.S. Fish and Wildlife Service. Carol Ferguson served as the coordinator for this project. We are grateful to the many organizations located on Guam and their employees who provided crucial data for this study: Art Perez, Joyce Sayama, Joaquin Flores, and Simon Camacho of Guam Power Authority; Sera Rios of Guam Memorial Hospital; Ernie Galito of the Guam Tourist Bureau; and Dan Vice, Craig Clark, and Jason Gibbons of Guam Wildlife Services. In addition, we thank the people and organizations that assisted our study in Hawai'i: Ronald Wong and Marc Matsuura of Hawaiian Electric Company; 
Pearl Imada Iboshi of the Hawai'i Department of Business, Economic Development, and Tourism; and Christy Martin of the Coordinating Group on Alien Pest Species.

\section{Literature Cited}

Blair, J. P. 1995. Local economic development: Analysis and practice. Sage Publications, Thousand Oaks, California.

Bon, R. 2000. Economic structure and maturity. Ashgate Publishing Company, Williston, Vermont.

Born, W., F. Rauschmayer, and I. Bräuer. 2005. Economic evaluation of biological invasions: A survey. Ecol. Econ. 55:321336.

Bureau of Economic Analysis. 2008. Industry economic accounts, satellite accounts, travel and tourism. http://www.bea.gov/ industry/index.htm (accessed 2 September 2008).

Burnett, K. M., S. D'Evelyn, B. A. Kaiser, P. Nantamanasikarn, and J. A. Roumasset. 2008. Beyond the lamppost: Optimal prevention and control of the Brown Tree Snake in Hawaii. Ecol. Econ. 67:66-74.

Engeman, R. M., and D. S. Vice. 2001. Objectives and integrated approaches for the control of brown tree snakes. Integr. Pest Manage. Rev. 6:59-76.

Fritts, T. H. 1988. The Brown Tree Snake, Boiga irregularis, a threat to Pacific islands. U.S. Fish Wildl. Serv. Biol. Rep. 88 (31): $1-36$.

1990. Risks to infants on Guam from the bites of the Brown Tree Snake (Boiga irregularis). Am. J. Trop. Med. Hyg. 42:607-611.

- 2002. Economic costs of electrical system instability and power outages caused by snakes on the island of Guam. Int. Biodeterior. Biodegrad. 49:93-100.

Fritts, T. H., and D. Chiszar. 1999. Snakes on electrical transmission lines: Patterns, causes, and strategies for reducing electrical outages due to snakes. Pages 89-104 in G. H. Rodda, Y. Sawai, D. Chiszar, and H. Tanaka, eds. Problem snake management: The Habu and the Brown Tree- snake. Cornell University Press, Ithaca, New York.

Fritts, T. H., and M. J. McCoid. 1999. The threat to humans from snakebite by snakes of the genus Boiga based on data from Guam and other areas. Pages 116-127 in G. H. Rodda, Y. Sawai, D. Chiszar, and H. Tanaka, eds. Problem snake management: The Habu and the Brown Treesnake. Cornell University Press, Ithaca, New York.

Fritts, T. H., M. J. McCoid, and D. M. Gomez. 1999. Dispersal of snakes to extralimital islands: Incidents of the Brown Treesnake (Boiga irregularis) dispersing to islands in ships and aircraft. Pages 209223 in G. H. Rodda, Y. Sawai, D. Chiszar, and H. Tanaka, eds. Problem snake management: The Habu and the Brown Treesnake. Cornell University Press, Ithaca, New York.

Fritts, T. H., M. J. McCoid, and R. L. Haddock. 1994. Symptoms and circumstances associated with bites by the Brown Tree Snake (Colubridae: Boiga irregularis) on Guam. J. Herpetol. 28:27-33.

Fritts, T. H., and G. H. Rodda. 1998. The role of introduced species in the degradation of island ecosystems: A case history of Guam. Annu. Rev. Ecol. Syst. 29:113140.

Fritts, T. H., N. J. Scott Jr., and J. A. Savidge. 1987. Activity of the arboreal Brown Tree Snake (Boiga irregularis) on Guam as determined by electrical outages. Snake 19:51-58.

Guam Power Authority. 2008. Fact sheet. http://www.guampowerauthority.com/ about/factsheet.html (accessed 2 September 2008).

Haddock, R. L., and O. L. T. Cruz. 1996. Animal bites and stings on Guam. Pac. Health Dialog 3 (1): 20-24.

Hawaiian Electric Company. 2008. Undergrounding utility lines: FactsSheet. www .HECO.com (accessed 2 September 2008).

Hawai'i Department of Business, Economic Development, and Tourism. 2003. The economic contribution of Waikiki. DBEDT e-report. http://hawaii.gov/ dbedt/info/economic/data_reports/e-reports/ 
econ_waikiki.pdf (accessed 2 September 2008).

. 2004. 2002 and 2003 Hawaii cruise industry impact study. http://hawaii.gov/ dbedt/info/visitor-stats/econ-impact/cruiseimpact.pdf (accessed 2 September 2008).

. 2007. Annual visitor research report: www.Hawaii.gov/dbedt (accessed 14 September 2006, 20 March 2007, and 14 December 2007).

- 2008. The 2005 state input-output study for Hawaii. http://hawaii.gov/dbedt/ info/economic/data_reports/2005_state_io/ 2005-input-output-study.pdf (accessed 2 September 2008).

Knowler, D., and E. B. Barbier. 2000. The economics of an invading species: A theoretical model and case study application. Pages 70-93 in C. Perrings, M. Williamson, and S. Dalmazzone, eds. The economics of biological invasions. Edward Elgar Publishing, Cheltenham, United Kingdom.

Kraus, F., and D. Cravalho. 2001. The risk to Hawai'i from snakes. Pac. Sci. 55:409-417.

Lahr, M. L., and E. Dietzenbacher. 2001. Input-output analysis: Frontiers and extensions. Palgrave Publishers, New York.

Lim, C. 2006. A survey of demand modeling practice: Issues and implications. Pages 45-72 in L. Dwyer and P. Forsyth, eds. International handbook on the economics of tourism. Edward Elgar Publishing, Cheltenham, United Kingdom.

Loomis, J., and G. Helfand. 2001. Environmental policy analysis for decision making. Kluwer Academic Publishers, Dordrecht.

McCann, P. 2001. Urban and regional economics. Oxford University Press, Oxford.

Olson, L. 2006. The economics of terrestrial invasive species: A review of the literature. Agric. Resour. Econ. Rev. 35:179-194.

Perrings, C., S. Dalmazzone, and $M$.
Williamson. 2005. The economics of biological invasions. Pages 16-35 in $\mathrm{H}$. A. Mooney, R. N. Mack, J. A. McNeely, L. E. Neville, P. J. Schei, and J. K. Waage, eds. Invasive alien species: A new synthesis. SCOPE, Island Press, Washington.

Perrings, C., M. Williamson, and S. Dalmazzone. 2000. Introduction and conclusions. Pages 1-16, 227-240 in C. Perrings, M. Williamson, and S. Dalmazzone, eds. The economics of biological invasions. Edward Elgar Publishing, Cheltenham, United Kingdom.

Pimentel, D., R. Zuniga, and D. Morrison. 2005. Update on the environmental and economic costs associated with alieninvasive species in the United States. Ecol. Econ. 52:273-278.

Rodda, G. H., T. H. Fritts, and D. Chiszar. 1997. The disappearance of Guam's wildlife: New insights for herpetology, evolutionary ecology, and conservation. BioScience 47:565-574.

Rodda, G. H., M. J. McCoid, T. H. Fritts, and E. W. Campbell III. 1999. Population trends and limiting factors in Boiga irregularis. Pages 236-253 in G. H. Rodda, Y. Sawai, D. Chiszar, and H. Tanaka, eds. Problem snake management: The Habu and the Brown Treesnake. Cornell University Press, Ithaca, New York.

Savarie, P. J., and R. L. Bruggers. 1999. Candidate repellents, oral and dermal toxicants, and fumigants for Brown Treesnake control. Pages 417-422 in G. H. Rodda, Y. Sawai, D. Chiszar, and H. Tanaka, eds. Problem snake management: The Habu and the Brown Treesnake. Cornell University Press, Ithaca, New York.

Savidge, J. A. 1987. Extinction of an island forest avifauna by an introduced snake. Ecology 68:660-668.

U.S. Census Bureau. 2007. www.census.gov. 